them possible with pigments; and applying these to the Maxwell rotating disks, with the addition of black and white, we can make and accurately name a very large proportion of all the colors found in nature which also agree somewhat nearly with similar pigmentary compositions.

As above stated, this system of color instruction includes a practical nomenclature of color nerer before advanced, which bas already been explained by Professor Pillsbury. Professor A. H. Church of the Royal Academy of Arts, in a series of lectures before the Society of Arts, London, an account of which has been published in this country, urges a scientific consideration of color in its application to art, and near the close of one of his lectures he says :-

"We want an international color conference, in which artists, manufacturers, and scientists shall be represented. We want an agreement upon the name to be assigned to a number of different hues. We want representations of these hues reproduced in enamel, preserved like our standards of weights and measures, and distributed to every educational institution in the United Kingdom. . . . The importance of having a definite nomenclature of quite intelligible character at our disposal when we are talking or writing about the decorative employment of color is so important that I venture to make a few suggestions which may tend toward the attainment of this object."

After making a suggestion for a method of notation, Professor Church adds: -

"The corresponding modifications in the five other principal series of colors would be expressed in a similar manner, the symbols, etc., being used exactly in the same way as in chemical no. tation. In order to obtain a scale in a concrete form I would recommend the use of Maxwell's rotation method by which each step in the gradation could be matched."

This author next proceeds to give a nomenclature of colors, but as it is based on the three primary colors of the scientist, namely, red, green, and violet, and the introduction with them of such additional terms as sea-green for a symbol, it is neither as simple nor as definite as the one which has been described in your article to which I have referred. This nomenclature is based solely on nature $s$ standards as found in the solar spectrum. Should we be favored with the international conference suggested by Professor Church, and should such a conference adopt the six standards and definitely locate them in the spectrum by their wave lengths, the world would then have standards which are the same in one country as in another, and would remain the same in the twentieth century as in the nineteenth.

As a manufacturer of an extended line of colored papers I am constantly putting this proposed nomenclature to a severe test by ordering new colors by telepbone. That is to say, we make the desired combinations on the wheel in our office and then telephone them to the factory, ten miles distant, where they are again made on the wheel and the papers are then manufactured to correspond with the results of these combinations. Under this plan we are liable to have occasion to "telephone a color" frequently. In the same way we could cable colors to Europe should it be necessary. MILton BradLey. Springfeld, Mass., March 17.

\section{Professor Alexander Agassiz on the Origin of the Fauna and} Flora of the Galapagos Islands.

IN the "Generol Sketch of the Expedition of the 'Albatross' from February to May, 1891" (Bull. Mus. Comp., Zool.. Harvard College, Vol. xxiii., No. 1, Cambridge, Feb., 1892) Professor Alex. ander Agassiz refers to my paper " On the Origin of the Galapagos Islands" (Am. Nat., March-April, 1891). There are some fundamental misunderstandings of my statements in Profescor Agassiz's remarks, which need correction.

Page 71, he says: " $\mathrm{He}$ [Baur] speaks of the Galapagos as being connected with the mainland by the 4,000-meter line." Then he adds "This [the connection of the Galapagos with South America] is an important fact; all the older maps showed the Galapagos separated from Central America" (!). To this I hare to reply, that I never expressed the opinion that the Galapagos were former- ly connected with South America. The same is repeated by Professor Agassiz in two other passages (p. 71).

In all my statements in regard to the land connections I was very cautious, as will be seen from p. 310: “In their general characters the fuana and flora of the Galapagos show resemblances to the great Mexican and Sonoran province, and also to the West Indies, and it may be that the connection was with these regions (and it seems more probable than any other), but of course it is quite impossible to bring to-day any positive proof for this idea." (The italics are mine.)

According to Professor Agassiz the proof of my subsidence theory " is based on no better evidence than the so-called alpine character of parts of the flora and upon the presumed former connection of the Galapagos Islands with the Central American continent." Professor Agassiz has completely overlooked the main point of my argument. This I considered the harmony in the distribution of fauna and flora, as will be seen by referring to my paper. I tried to show that this harmony was absolutely unexplainable by the theory of eleration. After this was done, I examined whether our present knowledge of the soundings showed any serious obstacle to the theory of subsidence, and I found that it did not. Professor Agassiz did not refer with one word to this harmony of distribution, which formed the basis of my whole ideas!

When Professor Agassiz or any one else is able to explain this by the elevation theory, I shall be the first one to adopt it. But until this has been done, I believe in subsidence.

The paper to which Professor Agassiz refers was written before my visit to the islands. My in restigations have only more convinced me of the insufficiency of the elevation theory. In my final work I shall speak fully about this question and about other points in Professor Agassiz's article.

Clark University, Worcester, Mass., March 15.

G. BAUR.

\section{The Scientific Alliance.}

I HEARTILY agree with your leading article of March 11, and trust that you will continue to press this subject. The further co-operation of the scientific societies in this city will result, I feel confident, in increased activity and effectiveness in each.

The special needs of many branches of work now being carried on here are more funds for publication and for first-class illustration. There is no national publication open to all papers of merit, like the Royal Society Transactions. The only journal I know of which provides liberally for illustration is Whitman and Allis's Journal of Morphology, and this is now, I have learned, overstocked for two years to come with biological papers of a high class.

Biol. Dept., Columbia College, March 18. HENRY F. OSBORN.

\section{BOOK-REVIEWS}

Travels amongst the Great Andes of the Equator. By EDWARD WhYMPER. New York, Scribner's. $8^{\circ}$. \$6.

A MONG the fascinating books of Professor Tyndall's is one on "Hours of Exercise in the Alps," in which, among other matter, he records the several unsuccessful attempts be made to ascend the Matterhorn, and how the rope left, by his parțs, hanging over a ridge of rocks enabled the next following party of climbers headed by Edward Whymper to gain such adrantage as to be able to reach the top. This first success was marred by a terrible tragedy, only three or four of the party of seven getting back to the foot of the mountain alive.

But Edward Whymper added another triumph to his record as a mountain climber in his being the first to reach the summit of Chimborazo in 1879 . It is the account of his journey at that time that is now published.

A hundred years ago the natives of the ralley of Chamonix who took travellers up the mountain suffered as much as their employers from physical sensations ascribed, no doubt rightly, to the rarity of the air. They were unable to walk more than a few paces without balting. Last autumn travellers who walked in early morning from the hut under the Bosses $(14,000$ feet) to the top (15,780 feet) had the company of fire Chamoniards. They 


\section{Science}

\section{Professor Alexander Agassiz on the Origin of the Fauna and Flora of the Galapagos Islands}

G. Baur

Science ns-19 (477), 176

DOI: 10.1126/science.ns-19.477.176

ARTICLE TOOLS

PERMISSIONS http://science.sciencemag.org/content/ns-19/477/176.1.citation

http://www.sciencemag.org/help/reprints-and-permissions 